\title{
CUESTIONES QUE SUSCITA LA PERSECUCIÓN DEL DELITO DE CONTAMINACIÓN ATMOSFÉRICA
}

\section{Luis Fernando Rey Huidobro}

Fiscal. Doctor en Derecho. Profesor de Derecho

Penal de la Universidad de Navarra. (España)

El artículo 325 del Código Penal español dice: "Será castigado con las penas de prisión de seis meses a cuatro años, multa de ocho a veinticuatro meses e inhabilitación especial para profesión u oficio por tiempo de uno a tres años el que, contraviniendo las leyes u otras disposiciones de carácter general protectoras del medio ambiente, provoque $\circ$ realice directa $\circ$ indirectamente emisiones, vertidos, radiaciones, extracciones o excavaciones, aterramientos, ruidos, vibraciones, inyecciones 0 depósitos, en la atmósfera, el suelo, el subsuelo, o las aguas terrestres, marítimas o subterráneas, con incidencia, incluso, en los espacios transfronterizos, así como las captaciones de aguas que puedan perjudicar gravemente el equilibrio de los sistemas naturales. Si el riesgo de grave perjuicio fuese para la salud de las personas, la pena de prisión se impondrá en su mitad superior.

\section{1.- INTRODUCCIÓN}

El artículo 325 del Código Penal, contempla como acción típica, la contaminación de determinados elementos naturales del ecosistema, como son el aire, el agua y el suelo, llevada a cabo a través de las múltiples formas mencionadas en el mismo.

Si la atmósfera es la masa de aire que rodea al planeta tierra, por contaminación atmosférica, a efectos del artículo 325 del Código Penal debemos entender la presencia en la misma de sustancias o agentes que no tienen un origen natural, sino que son provocados por la actividad humana y que ejercen influencia perniciosa sobre la existencia y desarrollo de los seres vivos presentes en el habitat que conforma el medio ambiente, incluido el hombre. Las sustancias o agentes que aquí interesan deben tener, por tanto, carácter nocivo o tóxico.

Dentro de los componentes de la contaminación atmosférica comprendida en el artículo 325 del Código Penal, debemos incluir, además de las emisiones a la atmósfera de sustancias químicas tóxicas, e: ruido, las vibraciones y las radiaciones (con o sin materia). Algunos de los componentes como son el ruido, las vibraciones y las radiaciones sin materia ( $v$.gr. ondas electromagnéticas) no son sustancias, y por ello es más correcto denominarlos agentes. 
Hay autores que consideran la redacción empleada por el legislador en el artículo 325 como demasiado descriptiva, reiterativa y confusa, impidiendo con ello la inclusión en el tipo de cualesquiera otras formas de contaminación realizadas a través de un medio que, aun acreditando cualificada capacidad contaminante, no resulte formalmente subsumible en el respectivo marco de los epítetos empleados en el tipo penal, como por ejemplo ocurre con la deforestación. Subrayando la reiteración típica, se sostiene, que tanto los ruidos, como las vibraciones y radiaciones (como manifestaciones de la contaminación atmosférica) cabrían dentro del vocablo "emisión".

(El motivo de limitarme a analizar la causalidad y la imputación objetiva en el delito de contaminación atmosférica, reside en que su investigación suele originar mayores problemas que los que plantean las investigaciones por contaminaciones de medios líquidos o sólidos, y que vamos a intentar analizar a continuación.)

\section{2.- LA RELACIÓN DE CAUSALIDAD}

\section{A.- En qué consiste.}

En el delito tipificado en el artículo 325 del C.P., lo único que hay que demostrar desde la perspectiva causal, es la fuente fisico-natural de la emisión, vertido etc. Hay que demostrar que los mismos se deben a conductas causales de un sujeto determinado, y se debe constatar qué comportamiento humano lo provocó. Este proceso es previo a cualquier posible imputación posterior. Sobre dicha relación, deberán proyectarse luego, los fenómenos de imputación comisiva y omisiva, el juicio de peligro o imputación objetiva y la imputación subjetiva.

Ya en esta fase puramente causal, pueden surgir problemas de difícil solución en el delito de contaminación atmosférica. Pensemos por ejemplo, en el caso (real por otra parte) de detección de una intoxicación de los trabajadores de una fábrica por humos tóxicos, procedentes presuntamente de otra fábrica ubicada en las inmediaciones. Para atribuir a los responsables de la primera industria la realización de una emisión típica desde la perspectiva penal, será necesario constatar en primer lugar un nexo de causalidad entre los humos que emana esa industria y la presencia de sustancias

\footnotetext{
"Véanse, POLAino NAVARRETE, M., "Delitos contra el medio ambiente en el Código Penal Español de 1.995". en Estudios juridicos en Memoria del Prof. Dr. D. José Ramón Casabó Ruiz, 2 vol., Valencia 1.997, pp605 y s; ALMELA VICH, C., "El medio ambiente y su protección penal", en Actualidad Penal, Tomo 1, 1.998, pp. 30 y s; SILVA SANCHEZ, J. M. Delitos contra el medio ambiente, Ed. Tirant lo Blanch, Valencia, 1.999, pp. 42 y s

2 Véanse, SILVA SÁNCHEZ, J. M., Delitos contra el medio ambiente, o. c. Pp. 44 y ss; DE LA CUESTA AGUADO, P. M.. Causalidad de los delitos contra el medio ambiente, Ed. Tirant lo Blanch, Valencia, 1.995, pp. $119 \mathrm{ys}$
} 
químicas altamente contaminantes en la atmósfera del lugar, excluyendo otras causas, como pueden ser, los humos de la industria donde trabajan los propios afectados, o el traslado de la contaminación por efecto del viento desde otros lugares.

\section{B.- Problemas derivados de la constatación del hecho de la contaminación.}

No es lo mismo medir el nivel de contaminación que origina un vertido sólido o líquido que el que origina una emisión a la atmósfera. Los vertidos sólidos o líquidos pueden ser recogidos, analizados y conservados más fácilmente que las emisiones a la atmósfera, las cuales requieren unas técnicas de investigación mucho más sofisticadas y complejas. En la constatación de contaminaciones atmosféricas, no sólo se deben medir las emisiones, es decir, las impurezas o toxicidades que produce la boca productora de la emanación ( $\mathrm{v}$.gr, chimenea), sino también las inmisiones de partículas, una vez que los vertidos gaseosos ya se han mezclado en su nuevo ambiente. ${ }^{3}$ Estas mediciones requieren la posesión de unos elevados conocimientos técnicos y unos sofisticados instrumentos de los que carecen aun los miembros de las Fuerzas y Cuerpos de Seguridad Centrales y Autonómicos encargados de la persecución de estos delitos (Servicio de Protección de la Naturaleza de la Guardia Civil, Mossos d Esquadra en Cataluña, Ertzaintza en el País Vasco, Policía Foral en Navarra etc). Es preciso ampliar la dotación personal y material de las policías encargadas de la persecución de este tipo de infracciones y no regatear esfuerzos en su correcta formación, con el fin de que puedan actuar con eficacia en todos los complejos sectores que conforman el medio ambiente y no como ocurre ahora, que quede reducida su actuación a la recogida de muestras e investigación de vertidos sólidos o líquidos a la tierra o a las aguas. Ello contribuiría no sólo a evitar la impunidad de estos delitos, sino también a mejorar la imagen de la policía entre aquellos sectores de la población que hasta ahora se han mostrado adversos hacia la misma, con actitudes que van desde el escepticismo hasta el rechazo, es decir, entre adolescentes y jóvenes radicales.

C.- Problemas derivados del traslado de la contaminación; la incidencia en los espacios transfronterizos.

En la contaminación atmosférica, puede ocurrir que los factores meteorológicos provoquen que el resultado contaminante final se produzca en un lugar diferente al lugar del que surgieron las emisiones contaminantes a la atmósfera. Esto suele ocurrir, por ejemplo, con las emisiones a la atmósfera de anhídrido sulfuroso (SO2), que

\footnotetext{
${ }^{3}$ Véase, QUERALT JIMÉNEZ, J.J., Derecho penal español, Parte especial, $3^{\circ}$ ed., J.M. Bosch Editor, Barcelona, 1.996, p. 718

“Véase, MULLER-TUCKFELD, J. C., Ensayo para la abolición del Derecho penal del medio ambiente, en La insostenible situación del Derecho penal, Estudios de Derecho penal dirigidos por C.M. Romeo Casabona, Ed. Comares, Granada, 2.000 , pp. 519 ys
} 
reacciona con la humedad existente en el aire y tras una serie de procesos químicos, se convierte en ácido sulfúrico que vuelve a la tierra vehiculizado por una lluvia con un bajo p. h. (denominada lluvia ácida).

El legislador, consciente de este problema, permite en el artículo 325 la efectiva imputación del resultado contaminante producido físicamente más allá de nuestras fronteras, por conductas realizadas en nuestro territorio nacional, aludiendo expresamente a la incidencia en los espacios transfronterizos.

Ya en el año 1.972, durante la Conferencia de Estocolmo, se llamó la atención sobre este problema, $\sin$ llegar a plasmarse, sin embargo, normas compulsivas que hiciesen frente al mismo. Hasta el año 1.979 no aparece lo que luego será el principal instrumento jurídico que aborda esta cuestión a nivel internacional, que es el Convenio sobre Contaminación Atmosférica Transfronteriza a gran distancia firmado en Ginebra el 13 de noviembre de 1.979, que fue el que incentivó la puesta en marcha de mecanismos nacionales que diesen solución a los problemas que genera la contaminación atmosférica cuya repercusión se reconoce internacionalmente como no limitada al territorio en que se produce, sino que afecta por su propia entidad y características a la tierra en su conjunto.

No tenemos constancia de que la contaminación transfronteriza a nivel internacional haya motivado la incoación de diligencias penales en nuestro país, sin embargo, a nivel interno, sí han surgido problemas competenciales entre juzgados de instrucción de diversas localidades a la hora de instruir diligencias para conocer de estos delitos. Así sucedió por ejemplo, entre el Juzgado de Instrucción $n^{\circ} 1$ de Vinaroz (Castellón) y el de Instrucción $n^{\circ} 1$ de Alcañiz (Teruel) para conocer de un presunto delito contra el medio ambiente (que luego resultaría sobreseido) contra la Empresa Nacional de Electricidad S.A. (Endesa), por emanaciones tóxicas de una central térmica de su propiedad ubicada en Andorra (Teruel). La Sala Segunda del T.S. resolvió la cuestión de competencia que se suscitó entre ambos juzgados, mediante el Auto de fecha 22 de diciembre de 1.993, en el que se resalta que "si la actividad criminal y la actividad dinámica de los hechos se propician en el lugar en donde la fábrica tiene sus instalaciones y en donde las emanaciones tóxicas se desarrollan, el tipo penal queda consumado desde que las emanaciones o vertidos, contraviniendo las normas protectoras del medio ambiente, ponen en peligro grave la salud de las personas - pueden perjudicar las condiciones de vida animal, bosques espacios naturales o plantaciones útiles (regía el C.P. de 1.973). Y ello en el terreno de las presunciones, tuvo lugar en donde la fábrica radica. Otra cosa es que los efectos de las emanaciones tóxicas se manifiesten en distintos lugares, o incluso que los principales daños se causen en otro territorio judicial". El T.S. subraya que salvo en los delitos de imprudencia (que no es el caso), la consumación plena se perfecciona en donde las emanaciones se producen. En consecuencia, declara competente para conocer de la causa al Juzgado 
de Alcañiz (Teruel), lugar donde se originó la emanación de la fábrica que presuntamente quebrantó la normativa medioambiental considerado como el "forum delicti comisi". Tal interpretación es, por otra parte, común a los delitos de riesgo o mera actividad regulados en el Código Penal.

No estimamos correcta, por el contrario, la postura doctrinal que considera la alusión a los espacios transfronterizos en el artículo 325, como una regla relativa a la competencia, que introduce una excepción al principio de territorialidad de aplicación de la norma penal, y que con ello se confiere competencia a los tribunales españoles para conocer de agresiones graves a nuestro medio ambiente, desde espacios no sujetos a la soberanía estatal ${ }^{6}$. Pienso, que lo único que se recoge en el artículo 325 con semejante fórmula, es que el delito se produce aunque la lesión o el peligro de lesión para el equilibrio de los sistemas naturales o para la salud de las personas, se produzca más allá de nuestro espacio fronterizo.

D.- Problemas causales derivados de la conducta del sujeto activo.

Uno de los grandes problemas que plantea la investigación causal de las contaminaciones atmosféricas, es, que se presta a manipulaciones por parte del empresario o encargado de la actividad o industria contaminante, muy difíciles de detectar. Por ejemplo, existen industrias de tratamiento de residuos tóxicos y peligrosos mediante la incineración, que los transforman en cenizas, escorias (compuestos inorgá nicos semifundidos y enfriados) y gases ${ }^{7}$. Los gases que producen, en principio no son tóxicos si se mantiene la combustión del residuo a una temperatura elevada $\left(1.500^{\circ}\right.$ por ejemplo) durante varias horas, pero los mismos, son sumamente tóxicos y nocivos si se reduce el tiempo de combustión o la temperatura de ignición. Pues bien, existen empresarios carentes de escrúpulos, que con el fin de reducir costes de producción y con ello aumentar beneficios, recortan el tiempo mínimo de combustión o bajan la temperatura de la misma, emitiendo con ello a la atmósfera gases muy perjudiciales para el medio ambiente y para la salud de las personas. Sin embargo, dado que para demostrar este hecho, es preciso practicar una medición de emisiones e inmisiones gaseosas en el momento en el que se produce la alteración, al empresario, administrador o encargado de la industria incineradora, le bastará con disponer que se practique una combustión correcta en el instante en que se lleven a

${ }^{5}$ Vé ase, PÉREZ DE GREGORIO, J. J., "El delito ecológico: aspectos jurisprudenciales", en Revista del Ministerio Fiscal, N³, Enero-Junio 1.996 , p. 316

En este sentido, ZUBIRI DE SALINAS, F., "Delitos contra el medio ambiente, en Empresa y Derecho penal (II)", Cuadernos de Derecho Judicial, 1.998, p. 103, añade que la tutela penal en estos supuestos, debe hacerse a trevés de una modificación de la L.O.P.J. (art.23), y no mediante la introducción de elementos objetivos en los tipos penales que tienen una finalidad distinta.

${ }^{7}$ Sobre la incineración como gestión de resíduos, véase, RUIZ DE APODACA ESPINOSA, A., "Derecho ambiental integrado: la regulación de los lodos de depuradora y de sus destinos". Ed. Civitas, Madrid, 2001, pp. 255 y ss 
cabo las referidas mediciones, para evitar la constatación de la toxicidad que viene generando, e impedir así la demostración de la causa de la contaminación. Lo mismo cabría decir por ejemplo con respecto a las radiaciones electromagnéticas que emiten antenas de telefonía móvil ubicadas en núcleos urbanos, ya que la potencia de la radiación es susceptible de manipulación. Luego, parece que en ocasiones sería conveniente practicar mediciones que sean desconocidas por el industrial o empresario que está siendo investigado, o incluso, recurrir a policías que actúen como agentes encubiertos, única manera a veces, de demostrar este tipo de manipulaciones.

\section{3.- LA IMPUTACIÓN OBJETIVA DEL RESULTADO}

\section{A.- La imputación objetiva en estos delitos.}

Debemos partir de la base de que el problema del resultado, no es exclusivo de los llamados delitos de resultado naturalístico, sino que es un problema general de todos los delitos sean de lesión o de peligro. Se trata de establecer si la conducta afectó al bien jurídico. Desde el punto de vista garantista, se trata de comprobar si se cumple el axioma, o lo que debería ser un axioma, "nullum crimen sine iniuria" con el que se expresa el principio de lesividad.

No olvidemos por otra parte, que en los delitos de resultado, éste puede consistir, bien en la lesión efectiva del bien jurídico, bien en la puesta en peligro concreto de dicho bien, pues la opinión doctrinal común considera el peligro concreto como un resultado ${ }^{8}$.

En el caso del artículo 325 del C.P., en la medida en que la consumación exige la puesta en peligro, una vez constatada la causalidad y la tipicidad del hecho, se trata de establecer si la acción peligrosa para el bien jurídico se plasmó "ex post" en un riesgo efectivo para el bien jurídico medio ambiente. Dicho de otra forma, si ese riesgo efectivo es obra del autor.

Como no se trata de un resultado material apreciable en el mundo de los sentidos, sino de un resultado fuera del mundo sensible, el mismo sólo puede ser comprobado intelectualmente, en el mundo de "lo que puede ser pensado" de lo

\footnotetext{
"Así, MANZANARES SAMANIEGO, J. L., "Los delitos contra el medio ambiente en el Código penal español", en Actualidad Penal, $n^{\circ} 1$ 1. 1.994, p. 11; DE LA CUESTA AGUADO, P. M., "Imprudencia y energía nuclear", en La Ley Año XXI, $n^{2}$ 5020, 24 de marzo de 2.000, p. 3; SILVA SÁNCHEZ, J. M., Delitos contra el medio ambiente, Ed. Tirant lo Blanch, Valencia, 1.999, pp. 74 y ss: expone en este texto las dudas que suscita entre la doctrina penal el artículo 325. Para unos se trata de un delito de peligro concreto, para otros de peligro abstracto. Entiende que, en todo caso, hay que excluir la postura que pretende hacer del delito contra el medio ambiente un delito de peligro presunto.
} 
inteligible ${ }^{9}$. Es éste un problema valorativo, que debe ser resuelto con criterios valorativos, de ahí que no sea correcto condicionar la tipicidad del delito ecológico a la producción de un resultado dañoso, como han hecho algunas resoluciones jurisprudenciales ${ }^{10}$. Lógicamente, la producción del resultado gravemente lesivo para los recursos naturales, puede ser una prueba evidente de que la acción resultaba peligrosa para los mismos, pero si el peligro o posible perjuicio se objetivizan, estaremos ante delitos de lesión que se castigarán separadamente (en tal sentido se pronunció la S.T.S. de 11 de marzo de 1.992).

La teoría de la "conditio sine qua non", pensada para la solución de los problemas en el mundo sensible, no sirve para solucionar los problemas propios de afección del bien jurídico "peligro grave para el equilibrio de los sistemas naturales", que deben ser resueltos como antes apuntaba, con criterios valorativos. La imputación del resultado debe ser argumentada con los criterios que suministra la teoría de la causalidad adecuada o de la idoneidad de la conducta, entendida no como una teoría de la causalidad, sino como un principio de imputación ${ }^{11}$. En este contexto, Silva considera a la teoría de la idoneidad concreta "ex ante" como la que resulta más coherente en términos sistemáticos-teleológicos ${ }^{12}$. Ello supondría, que como filtro previo, para poder imputar el peligro para el medio ambiente a la conducta que lo realiza, sería necesario que en el momento de llevar a cabo la misma por el sujeto, sea previsible para una persona ideal objetivamente considerada, el riesgo que luego habrá de surgir al materializarse la misma, o lo que es lo mismo, debe darse un juicio "ex ante" de previsibilidad objetiva del comportamiento para producir el peligro grave para el medio ambiente o la salud de las personas ${ }^{13}$.

No existirá responsabilidad penal achacable al autor de la emisión o vertido, cuando los mismos no lleguen a producir peligro grave para el medio ambiente, aunque

${ }^{9}$ Cfr. HORMAZÁBAL MALARÉE, H., "El principio de lesividad y el delito ecológico, en El nuevo Derecho penal español", Estudeios penales en Memoria del Prof. José Manuel Valle Muñiz, Ed. Aranzadi, Pamplona, 2001, pp. 1427 y s.

${ }^{10}$ Así ocurrió en la Sentencia de la Audiencia Provincial de Sevilla de 12 de julio de 1.993, que descartó la tipicidad del comportamiento porque no se había podido demostrar que la muerte de las aves tenía su causa en los pesticidas. Bastaba con demostrar el peligro de los pesticidas para el medio ambiente. La muerte de las aves no era nada más que la manifestación social y perceptible del peligro y por tanto, un dato ajeno a la tipicidad. Véase al respecto, HORMAZÁBAL MALARÉE, H., El principio de lesividad y el delito ecológico, o. c. pp. 1427 y s.

in

Asi, HORMAZÁBAL MALARÉE, H., o. c. pp. 1427 y s; SILVA SÁNCHEZ, J. M., Delitos contra el medio ambiente, o. C. pp. 76 ys

${ }^{12}$ SILVA SÁNCHEZ, J.M. O. O.c. pp. 76 ys

${ }^{13}$ Véanse, MARTÍNEZ ESCAMILLA, M., La imputación objetiva del resultado, EDERSA, Madrid, 1.992, pp. 114 y ss; JAKOBS, G., Observaciones sobre la imputación objetiva, en Revista de Poder Judicial, $3^{2}$ é poca, N² 56, pp. 132 y s; GIMBERNAT ORDEIG, E., Delitos cualificados por el resultado y causalidad, Ed. Centro de Estudios Ramón Areces, Madrid, 1.990, pp. 36 y ss. 
si el sujeto lo había querido, cabría plantearse aquí la hipotética responsabilidad por tentativa de delito ${ }^{14}$.

B.- Problemas de imputación que plantean las contaminaciones atmosféricas de parajes ya contaminados previamente.

Particular interés muestran aquí aquellas contaminaciones de atmósferas que ya se encuentran contaminadas por otras emisiones o vertidos anteriores. En estos casos, no puede sostenerse, como hizo el Juzgado de lo Penal Número Dos de Sabadell en Sentencia de 21 de Julio de 1.995 , referida a la contaminación por vertidos de un río muerto (porque ya estaba contaminado), que no hay delito porque el bien jurídico medio ambiente ya estaba lesionado ${ }^{15}$. Entiendo, que aunque se acredite que el medio ambiente (atmosférico en nuestro caso) ya estaba en peligro por otras emisiones, basta con que se domuestre que la emisión en concreto superaba los límites legalmente permitidos, que por sí misma creaba un grave peligro para un determinado ecosistema, para que sea imputable penalmente al autor. La doctrina penal mayoritaria, sostiene que en los delitos de peligro concreto, a efectos de considerar a la acción juzgada como productora del resultado, carece de trascendencia el hecho de que hubieran concurrido otras acciones de otros sujetos, de forma dolosa, imprudente o incluso fortuita $^{16}$. Es indiferente, por tanto, que existan otras fuentes contaminantes, pues, si la acción es de por sí gravemente nociva e incrementa con ello la posibilidad de lesión, es indudablemente peligrosa a los efectos del artículo 325 del Código Penal, y es indiferente asimismo, que otros que también contaminan de modo penalmente relevante, consigan eludir el correr la misma suerte.

C.- La imputación y los factores aleatorios de la contaminación.

También deben permanecer ajenos a la responsabilidad penal factores aleatorios que pueden influir en la contaminación, tales como las circunstancias climáticas: v.gr. si la zona es más aireada o de difícil ventilación, la mayor o menor frecuencia de la Iluvia etc, ya que si tales circunstancias debieran ser tenidas en cuenta por el juzgador, harían prácticamente imposible la aplicación del tipo, pues en ese caso, lo que tendría relevancia para el Derecho penal, no sería tanto la emisión o vertido en sí propiamente

${ }^{14}$ Véase, ROXIN, CLAUS., La imputación objetiva en el Derecho penal, Trad. Manuel A. Abanto, Ed. IDEMSA, Lima (Perú), 1.997, pp. 27 y ss, y 112 y ss.

${ }^{15}$ Véanse, DE LA CUESTA AGUADO, P. M. Causalidad de los delitos contra el medio ambients, o.c., pp. 127 y s; VERCHER NOGUERA, A., "Reflexiones sobre las emisiones y vertidos en los delitos contra el medio ambiente y algunos aspectos determinantes en los mismos", en Revista Penal La Ley, $\mathrm{n}^{2} 7$, Enero 2.001, p. 103; SILVA SÁNCHEZ, J.M., Delitos contra el medio ambiente, o. C. Pp. 85 y ss; HOMAZÁBAL MALARÉE, H., El principio de lesividad y el delito ecológico, o. c. p. 1427.

16

Véanse, DE LA CUESTA AGUADO, P.M., Causalidad de los delitos contra el medio ambiente, o.c. pp. 127 y s; HORMAZÁBAL MALARÉE, H., El principio de lesividad y el delito ecológico, o. c. p. 1427 
dichos, sino su mayor o menor dilución en el aire (agua, suelo etc) pasando así a depender el peligro del hecho concreto de la dilución, que es en lo que se centraría la tipicidad. Como afirma Vercher, al hacerse depender la peligrosidad de la dilución de la emisión (o vertido) y no de la emisión (o vertido) en sí, nunca podría producirse un delito $^{17}$.

A mi modo de ver, sin embargo, los factores aleatorios tales como las circunstancias climáticas, sí podrían ser determinantes de la producción o no del tipo delictivo. Pensemos por ejemplo, en una emisión a la atmósfera de humos de contenido patógeno grave para la salud de las personas, casualmente en un día de fuertes vientos, que hacen que se disperse rápidamente su contenido nocivo, y que por ello evitan que esa conducta pueda causar graves perjuicios en el equilibrio de los sisternas naturales o en la salud de las personas, de necesaria producción en otro caso. $\mathrm{O}$ en un vertido tóxico en el cauce de un río, que por casualidad y coincidiendo con unos días de grandes lluvias o de fuerte deshielo, hace que lo que normalmente hubiese sido gravemente peligroso, no lo sea en ese momento y por ese casual motivo. Ello no es óbice, para que si el sujeto tenía la intención de cometer el delito y éste no se produjo por causas independientes a su voluntad, podamos hablar de la existencia de una tentativa de delito, pero nunca de un delito consumado, ya que el peligro hipotético que el tipo exige como resultado, no se produjo por causas ajenas a su voluntad.

\section{D.- La denominada causalidad acumulada o acumulativa.}

También pueden producirse en este contexto casos de la denominada causalidad acumulativa. En efecto, puede ocurrir que una fábrica produzca humos o emisiones en dosis no gravemente peligrosas para el medio ambiente, pero que acumuladas a otras producidas por otras industrias ubicadas en las inmediaciones, en su conjunto sí resulten peligrosas. De la Cuesta Aguado formula un ejemplo ilustrativo: supongamos que la industria E1 realiza una emisión de 1 gramos de la sustancia " $X$ "; Ez emite 2 gramos de la misma sustancia; y E3, en el mismo período de tiempo que las anteriores, emite también 1 gramo de " $X$ ". Se conoce, además, que la inhalación de más de 3 '5 gramos de aire de la sustancia " $X$ " es nociva para la salud y produce la enfermedad "K" o la muerte ${ }^{18}$. O también el supuesto de la fábrica que emite sustancias inocuas, pero que unidas a otras procedentes de terceras industrias, se convierten en nocivas.

En todos estos supuestos, existen efectos sinérgicos, que son los producidos por la combinación e interacción de dos o más efectos derivados del poder dinámico que ellos encierran, cuando por separado no tienen capacidad alguna para la producción de tales resultados.

\footnotetext{
${ }^{17}$ VERCHER NOGUERA, A., "Reflexiones sobre las emisiones y vertidos ..." o. c. p. 105

${ }^{18}$ DE LA CUESTA AGUADO, P. M., Causalidad de los delitos contra el medio ambiente, o. c. p. 86
} 
La doctrina mayoritaria entiende que es inadmisible sostener una imputación penal para el sujeto que realiza una de las conductas cumulativas, pues una sanción así, fundamentada, sería desde la perspectiva del Derecho penal "ex iniuria tertii", se habla en estos casos de peligro global, en tanto que cada situación contaminante carece de riesgo de entidad suficiente para ser relevante penalmente, con lo que deberá proceder la impunidad ${ }^{19}$. O dicho con otras palabras, cada sujeto debe responder de la parte de riesgo creado por separado. No se responde por el resultado de peligro acaecido, del que cada conducta es parte cocausante en sentido causal o natural, sino que se debe responder en atención a criterios normativos, al riesgo creado. Así, cada sujeto responderá por el riesgo concreto creado por su conducta, no por el resultado global o general de peligro que su conducta causa. Como afirma Jakobs, "la obra de una persona es el producto de su libertad, no el de la libertad de otros" ${ }^{20}$, y en estos casos, la libertad del que actúa no se objetiviza en el resultado que es producto de la actuación de terceros, por eso falta la imputación objetiva. Únicamente en aquellos supuestos en los que una única persona fuese la propietaria de todas las industrias contaminantes cabría pensar en una posible responsabilidad penal en estos términos. Sin embargo, quien contamina de modo penalmente relevante, realizando por ello un delito contra el medio ambiente, debe ser condenado aunque haya otros sujetos también contaminantes que consigan eludir la imputación penal.

La cuestión del título de imputación (dolosa o culposa) que cabría efectuar al autor, es algo que excede del ámbito de imputación objetiva, para pasar a la subjetiva.

No obstante, parece lógico que estas conductas sean sancionadas en el ámbito del Derecho administrativo, dado que la suma de emisiones (o vertidos) tendría un claro efecto lesivo.

No hay que olvidar tampoco aquí, la posible responsabilidad penal en que podría incurrir la autoridad o funcionario público encargado del control de la actividad (en base al artículo 329 del C.P. si es con dolo o del artículo 331 si es por culpa ${ }^{21}$ ), que

\footnotetext{
${ }^{19}$ Véanse, SILVA SÁNCHEZ, J. M., La expansión del Derecho penal. Aspectos de política criminal en las sociedades postindustriales, Ed. Cívitas, Madrid, 1.999. pp. 104 y ss. Del mismo autor, "¿ Protección penal del medio ambiente?. Texto y contexto del artículo 325 (I)", en La Ley, Año XVIII, $n^{9} 4285,12$ de Mayo de 1.997, p.3; IÑIGO CORROZA, M. E., La responsabilidad penal del fabricante por defectos de sus productos, J. M². Bosch Editor, Barcelona, 2.001, pp.328 y ss; JAKOBS, G., Observaciones sobre la imputación objetiva, o.c. pp. 119 y ss.

${ }^{20}$ JAKOBS, G., Observaciones sobre la imputación objetiva, o. u.c. p. 126

${ }^{21}$ Según algunos comentaristas, la prevaricación funcionarial recogida en el artículo 329 que requiere una actuación "a sabiendas" y que no admite comisión culposa es exclusivamente la participación en la concesión de licencias, no así por el contrario el silenciamiento de infracciones con motivo de inspecciones, que no requiere ningún elemento subjetivo del injusto. Asi, DE LA CUESTA ARZAMENDI, J. L., "Delitos contra los recursos naturales y el medio ambiente: Capítulo III, título XVI, libro II del Nuevo Código Penal de 1.995", en Actualidad Penal, Tomo $1,1.998$, pp. 304 y s.
} 
autoriza las emisiones en cuantías aisladamente no nocivas, pero conociendo de antemano la grave peligrosidad de las dosis en su conjunto, o bien que constatando esas dosis con posterioridad con motivo de una inspección, las hubiere silenciado. ${ }^{22}$ La tipicidad de su conducta en tales supuestos, dados los términos de redacción de los artículos 329 y 331 del Código Penal, debe quedar fuera de dudas. Cabría pensar incluso en un delito de comisión por omisión, dado el deber de garante que ostentan tales personas respecto de los bienes jurídicos protegidos en estos delitos.

\section{4.-LA PLURALIDAD DE ACTOS CONTAMINANTES: LA POSIBILIDAD DEL DELITO CONTINUADO}

El empleo del plural hipotético en la formulación de los tipos en el artículo 325 del C.P. (emisiones, vertidos, radiaciones, ruidos etc), no debe llevarnos hasta el punto de plantear la atipicidad de la provocación o realización de una única emisión, radiación etc, como ha llegado a plantear algún autor ${ }^{23}$, sino que el recurso al plural hipotético es algo habitual en la elaboración de la norma penal, sin que plantee, por lo general, mayores problemas interpretativos. Aun cuando la norma configure los elementos típicos en número plural, se interpreta como un simple rasgo de estilo, de forma que se entiende realizada la conducta descrita con la realización de una singular conducta.

Partiendo de la base de que una sola emisión, vertido etc, completa el tipo penal, se ha sostenido que una pluralidad de los mismos, imputables a una única actividad industrial y en periodos de tiempo sucesivos o correlativos, darán lugar a la apreciación de la continuidad delictiva y a la aplicación del artículo 74 del Código Penal $^{25}$, postura ésta por la que se han decantado también algunas resoluciones jurisprudenciales (v.gr. Sentencia de la Audiencia Provincial de Barcelona de 9 de Febrero de 1.993 y Sentencias de la Sala Segunda del Tribunal Supremo de 26 de Septiembre de 1.994 y 1 de Febrero de 1.997, a las que luego haré referencia).

A mi modo de ver, tal postura no es asumible, Por supuesto, que la no apreciación del delito continuado, no significa que sostenga que deben apreciarse una pluralidad de delitos en el caso de realizarse varios actos en sentido naturalístico, sino

\footnotetext{
22 Véanse, DE LA CUESTA AGUADO, P. M., Causalidad de los delitos contra el medio ambiente, o. c. p. 89 ; VERCHER NOGUERA, A., Reflexiones sobre las emisiones y vertidos en los delitos contra el medio ambiente $y$ algunos aspectos determinantes en los mismos, o. c. p. 102

${ }^{23}$ En tal sentido, BRIONES VIVES, "El delito ecológico", en Revista de Derecho ambiental, n² 3, p. 26.

${ }^{24}$ Véanse, BLANCO LOZANO, C., La protección del medio ambiente en el Derecho penal español y comparado, Ed. Comares, Granada, 1.997, pp. 204 y ss; SILVA SÁNCHEZ, J.M., Delitos contra el medio ambiente, o. c. p. 51

${ }^{25}$ En este sentido, PÉREZ DE GREGORIO CAPELLA, J. J., El proceso penal medioambiental, Ed. Centro de Estudios Ramón Areces S.A., Madrid, 1.999, pp. 43 y ss; BLANCO LOZANO, C., La protección del medio ambiente, o.c. pp. 206 y s.
} 
que no es posible la apreciación del delito continuado porque la continuidad delictiva ya está contenida en el tipo penal. El delito continuado requiere una delimitación concreta entre la voluntad del acto aislado y la voluntad del conjunto, delimitación que resulta aquí muy difícil por no decir imposible, ya que normalmente se dará la voluntad de contaminar de un modo genérico (aunque sea con dolo eventual), y no la de realizar un acto determinado contaminante. El legislador, consciente de estos postulados, describe los actos en plural (emisiones, radiaciones, vertidos etc) a la hora de enumerar las conductas típicas, por lo que en principio, resulta indiferente el número de acciones que se han llevado a cabo. Existe una equivalencia a efectos de sanción entre el acto único y su repetición o habitualidad. Ello es debido a que nos hallamos ante un tipo de los denominados mixtos alternativos, que se caracterizan porque una sola infracción normativa se desdobla en distintas proposiciones jurídicas ${ }^{26}$. Las diversas modalidades de conducta descritas, se encuentran recogidas bajo una misma amenaza penal en unidad legal. El legislador, ha incluido bajo una misma pena en el artículo 325 del Código Penal distintas modalidades de ataque al medio ambiente, porque no ha hallado una fórmula comprensiva que englobe a todos, pero queriendo representar cada una de ellas el mismo ataque al bien jurídico, es decir, encontrándose entre si en la relación que Binding denominó de alternatividad.

Entiendo que tampoco se producirá una pluralidad de delitos ni un delito continuado, cuando concurran entre sí diversas formas de conducta descritas en el artículo 325 practicadas por un mismo agente contaminante, pues se trata simplemente de formas alternativas de previsión de una única conducta criminal, en las que la ley emplea diversas fórmulas para describir acciones que conllevan el mismo núcleo sustancial del ilícito. Así ocurriría por ejemplo, si el director de una industria de tratamiento de residuos tóxicos y peligrosos mediante su incineración, realizase emisiones altamente contaminantes simultáneamente con vertidos de residuos tóxicos sólidos que resulten gravemente peligrosos para los recursos naturales y el medio ambiente. Distinto sería, si las emisiones, vertidos etc, realizados por un mismo sujeto, se produjesen en fábricas y lugares alejados entre sí, en cuyo caso, sí cabría hablar de delitos plurales y distintos.

La jurisprudencia del Tribunal Supremo, si bien inicialmente y adoptando a mi parecer una posición errónea, se decantó por aceptar el delito continuado en estas infracciones (SSTS de 26 de Septiembre de 1.994 y 1 de Febrero de 1.997), posteriormente parece haber corregido esta postura, reconociendo que la reiteración de conductas típicas no produce el delito continuado ni multiplica el número de delitos,

\footnotetext{
${ }^{26}$ Véanse, GIL GIL, A., "Los tipos mixtos y su clasificación", en Revista de Derecho Penal y Criminología UNED, $2^{2}$ ÉPOCA, № extraordinario, marzo 2.000, pp. 77 y ss; ZAGREBELSKI, V., Reato continuato, Ed. Giuffrè, Milán, 1.979, pp. 211 y s.
} 
aunque no menciona su naturaleza de tipo mixto alternativo. Así, en la Sentencia de 12 de diciembre de 2.000 (ponente Sr. Delgado García), casa la Sentencia de la Audiencia Provincial de Barcelona que había apreciado un delito continuado contra el medio ambiente por vertidos tóxicos de aguas residuales y lixiviados sin depuración ni tratamiento, y dice que "nos hallamos, no ante un delito continuado, como erróneamente lo califica la sentencia de instancia, sino ante lo que un sector de la doctrina llama tipo que incluye conceptos globales, en los que se describe la correspondiente infracción por medio de unos términos que abarcan en su seno una pluralidad que integran un solo delito". Efectúa una equiparación con los actos típicos recogidos en el delito de tráfico de estupefacientes (art. 368 C.P.) el de falsificación de moneda (arts 386 y 387) y el de sellos de correos o efectos timbrados (art.389), y continúa diciendo: "varios vertidos procedentes de una misma actividad industrial o de otro tipo, encajan, pese a su pluralidad, en el mismo delito, porque a ello obliga la utilización en la correspondiente norma penal de un concepto global que abarca lo mismo un solo hecho u objeto que varios. Luego, el juzgado o tribunal, a la hora de graduar la pena dentro de los márgenes permitidos por el legislador, habrá de fijarla teniendo en cuenta, entre otros criterios para medir la gravedad del delito, la existencia o no de esa pluralidad y la importancia que ésta pueda tener en relación con las diversas circunstancias del hecho delictivo".

Esta cuestión, abre un debate adicional, como es, cuándo, tras una condena por un delito contra el medio ambiente, puede volverse a apreciar un nuevo delito contra el mismo bien jurídico, sin vulnerar el principio "ne bis in idem" procesal o de "cosa juzgada". Me parece acertada la solución que ofrece Silva Sánchez para estos supuestos, cuando sostiene que "podría estimarse que todos los vertidos o emisiones etc, comprendidos en el período enjuiciado, esto es, producidos hasta la última fecha de las contempladas expresamente en el proceso, están abarcados por la fuerza de la cosa juzgada. No, en cambio, los producidos después, aunque se hubieran cometido obviamente antes de dictar la sentencia por los anteriores ${ }^{27}$. El problema surge a la hora de precisar cuál debe ser la fecha límite que finaliza el período enjuiciado, si la fecha de iniciación de las diligencias judiciales, la fecha del escrito de la acusación, la del auto de incoación de procedimiento abreviado, la del auto de apertura de juicio oral, o la propia fecha del acto del juicio oral, como sostienen otros. Sobre esta cuestión existen múltiples posturas doctrinales , siendo a mi parecer la que resulta más plausible, la fecha del escrito de acusación, ya que añadir nuevas imputaciones en el acto del juicio oral podría provocar indefensión en el acusado.

\footnotetext{
${ }^{27}$ SILVA SÁNCHEZ, J. M., Delitos contra el medio ambiente, o.c. pp, 54 y s

${ }^{28}$ Véase, SILVA SÁNCHEZ, J. M., Delitos contra el medio ambiente, o. c. pp. 54 ys
} 
Fuera de la anterior hipótesis, entiendo que la habitualidad contenida en el tipo, quebrará asimismo, con el factor temporal, de tal manera, que la interrupción persistente de las actividades delictivas y su reemprendimiento después de cierto tiempo, podría provocar que nos hallemos ante delitos totalmente independientes.

\section{5.-LA DIFÍCIL IDENTIFICACIÓN DEL SUJETO ACTIVO}

Si bien el delito del artículo 325 del Código Penal es un delito común, al no exigir especiales elementos o condiciones de autoría, comunmente es realizado por sujetos que actúan en el seno de una empresa. En la empresa, nos hallamos ante una estructura organizada, basada en el plano horizontal, en el principio de división de trabajo $y$, en el plano vertical, en el principio de jerarquía. Todos sabemos que las actividades de las empresas, son típicamente el resultado de decisiones entrelazadas, con una tendencia a ensanchar la delegación de responsabilidades. Así se comprende que la conducta puramente ejecutiva no sea siempre la más relevante. De hecho la responsabilidad penal de los sujetos individuales en el marco de la empresa, muestra grandes similitudes con el problema que genera la determinación de la responsabilidad penal en el marco de la criminalidad organizada ${ }^{29}$.

En los delitos medioambientales no se puede pretender determinar el sujeto activo aplicando el artículo 31 del Código Penal (como a veces se ha hecho incluso por la jurisprudencia), ya que dicho precepto constituye un mecanismo creado exclusivamente para superar los problemas de imputación típica de los delitos especiales cometidos en el ámbito de personas jurídicas, y aquí nos hallamos ante un delito común. Lo que sí se debe demostrar, es quienes son las personas individuales (únicas responsables penales) que deben responder penalmente pertenecientes a la estructura de la persona jurídica, y para ello, es necesario servirse de las estructuras convencionales de imputación activa u omisiva para atribuir el hecho (en virtud de su dominio social sobre el mismo) a sujetos que, normalmente no serán quienes de modo directo hayan realizado la última aportación causal al mismo.

Tal es la complejidad que rige en las grandes empresas que poseen una extensa organización, que a veces puede resultar incluso imposible demostrar qué concretas personas individuales han provocado la realización del acto contaminante. No son raros los casos en los que constando la existencia del acto delictivo proveniente de una persona jurídica, se produce una absolución de los sujetos individuales en ella insertos e

\footnotetext{
${ }^{29}$ Véanse, CHO, BYUNG-SUN, "¿EI surgimiento de un Derecho penal internacional del Medioambiente?", en Revista Penal La Ley, $n^{2} 8$, Julio de 2.001, pp. 12 y ss; SILVA SÁNCHEZ, J. M., "Responsabilidad penal de las empresas y de sus órganos en Derecho español, en Fundamentos de un sistema europeo del Derecho penal", Libro-Homenaje a Claus Roxín, J.M Bosch Editor, Barcelona, 1.995, pp. 368 y ss.
} 
inculpados, por falta de pruebas concretas contra los mismos. Hasta tal punto esto es así, que los propios sujetos individuales que actúan en el marco de la empresa, pueden configurar y planear de antemano un sistema de irresponsabilidad organizada de los individuos por ella contratados.

También muestran aquí especial interés, figuras tales como la autoría mediata activa (art. 28, I del C.P.) y la autoría en comisión por omisión regulada en el artículo 11 del Código penal. A esta última alude la Sentencia del Tribunal Constitucional $62 / 1.994$, de 28 de febrero, en la que se desestima el recurso de amparo interpuesto por el Director de una fábrica, contra su condena por delito contra el medio ambiente cometido por omisión de ciertas exigencias técnicas y de la vigilancia debida.

6.- Dificultades que suscita la aplicación del tipo (art.325 C.P.), derivadas de su naturaleza de ley penal en blanco.

Frente a aquellos países que prevén una protección penal del medio ambiente absolutamente independiente de presiones administrativas (Dinamarca, Holanda, Portugal etc) y aquellos otros en los que el Derecho penal se configura de forma absolutamente dependiente de las normas administrativas, sancionando todo incumplimiento de las mismas (Belgica, Canada, Francia, E.E.U.U.etc), en el modelo adoptado por nuestro ordenamiento jurídico, la regulación penal aparece relativamente subordinada a la normativa o a la actuación administrativa ${ }^{30}$. Es decir, que se erige en infracción penal la contaminación que viole disposiciones legales o actos administrativos o la contaminación no autorizada legalmente. En el artículo 325 del Código penal se realiza una descripción general del comportamiento que pretende incriminarse penalmente, pero el injusto penal se completa con una remisión a la normativa administrativa, de ahí que nos hallemos ante una norma penal en blanco.

El recurso a esta técnica legislativa en estos delitos, ha sido fuertemente criticada por ciertos sectores de la doctrina penal, por estimar que puede vulnerar el principio de legalidad, provocando incluso la intervención del Tribunal Constitucional, con ocasión de un recurso de amparo en el que se sostenía que la estructura en blanco del derogado delito contra el medio ambiente del artículo 347 bis, vulneraba el principio de legalidad. El Tribunal Constitucional, resolvió la cuestión con la Sentencia $127 / 1.990$, de 5 de julio (ponente Sr. García-Mon), en la que manifestó que: "el artículo 347 bis y las leyes en blanco en general, son conformes a la Constitución siempre que se den los siguientes requisitos: que el reenvío normativo sea expreso y esté

\footnotetext{
${ }^{30}$ Véanse, DE LA MATA BARRANCO, N., "Configuración como ley penal en blanco de los delitos contra el medio ambiente", en Estudios jurídicos en memoria del Prof. Dr. José Ramón Casabó Ruiz, vol. I, Valencia, 1.997, pp. 578 y ss; SILVA SÁNCHEZ, J. M., Delitos contra el medio ambiente, o. c. p. 57 y ss; BLANCO LOZANO, C., La protección del medio ambiente en el Derecho penal español y comparado, Ed. Comares, Granada, 1.997, pp. 145 y ss
} 
justificado en razón del bien jurídico protegido por la norma penal; que la ley, además de señalar la pena, contenga el núcleo esencial de la prohibición y sea satisfecha la exigencia de certeza o, como señala la citada sentencia $122 / 1.987$, se de la suficiente concreción, para que la conducta calificada de delictiva quede suficientemente precisada con el complemento indispensable de la norma a la que la ley penal se remite, y resulte de esa forma salvaguardada la función de garantía del tipo con la posibilidad de conocimiento de la actuación penalmente conminada". En un sentido similar se pronuncia también la Sentencia del Tribunal Constitucional 62/1.994, de 28 de febrero, resolución ésta en la que se añade al respecto que: "la norma penal en blanco reúne los requisitos de la lex praevia, certa y scripta exigidos constitucionalmente, puesto que formula una remisión expresa y completa a normas específicas y define el núcleo esencial de la conducta prohibida, remitiéndose solamente para completar el tipo a una determinada circunstancia, con lo cual queda definido asimismo de modo suficiente este elemento, consistente en una infracción administrativa de normas que tengan aquella finalidad" ${ }^{31}$.

Como afirma Silva Sánchez, el efecto de la remisión no es permitir una ampliación de la responsabilidad penal habilitando a la Administración para hacerlo, sino al contrario, el reenvío opera en la práctica como elemento de restricción del ámbito de lo punible, pues una conducta peligrosa para el medio ambiente no podrá sancionarse penalmente si no existe ninguna norma sectorial que lo prohiba ${ }^{32}$.

El artículo 325 del Código penal ha sustituido la referencia a "leyes y reglamentos" del Código derogado (art. 347 bis) por la de "leyes u otras disposiciones de carácter general". Esta modificación tuvo lugar, para garantizar la inclusión entre las normas objeto de remisión a las emanadas de la Unión Europea ${ }^{33}$; y en segundo lugar, para abarcar disposiciones con carácter normativo, que sólo de modo impropio podrían caracterizarse como reglamentos, como son los planes y otras disposiciones en materia urbanística. Sin embargo, no podrán nunca integrar el tipo, las normas administrativas emanadas de los municipios, ya que la Administración local carece por

${ }^{31}$ Véase, BLANCO LOZANO, C., "La posible inconstitucionalidad de las normas penales en blanco", en La Ley, 8 de febrero de 2.001, p. 3

${ }^{32}$ SILVA SÁNCHEZ, J. M., Delitos contra el medio ambiente, o, c. p. 58

${ }^{33}$ La doctrina penal mayoritaria sostiene que mientras que tanto los Tratados como los Reglamentos europeos tienen una subsunción clara en el tipo, las Directivas no traspuestas no pueden ser utilizadas para integrar la remisión y fundamentar en base a las mismas una sanción penal, ya que se entiende que el Estado que pretende hacer valer una Directiva no incorporada al Derecho interno frente a sus ciudadanos, está yendo contra sus propios actos. En este sentido se pronunció el Tribunal de justiria de Luxemburgo en Sentencia de 11 de junio de 1.987, a tenor de un presunto delito por contaminación de las aguas del rio Chiese en Italia y muerte masiva de peces, ante la cuestión prejudicial planteada por el Juez de Instrucción italiano. Véanse, VERCHER NOGUERA, A., "La incidencia del Derecho comunitario en la protección penal del medio ambiente", en Actualidad Penal, n| 12, 1994, pp. 234 y ss; SILVA SÁNCHEZ, J. M., Delitos contra el medio ambiente, o. c. Pp. 60 y s; BLANCO LOZANO, C., La protección del medio ambiente en el Derecho penal español y comparado, o. c. pp. 154 y ss. 
disposición constitucional (art. 149. 1, 23) de competencia para dictar normas protectoras del medio ambiente. Esta exclusión puede tener importancia en sectores como el de contaminación atmosférica por ruidos, en el que han surgido multitud de normas municipales ${ }^{34}$.

Sin embargo, la dispersión de la normativa administrativa ambiental (y la atmosférica no es una excepción) entre diversos ordenamientos jurídicos (internacional, comunitario, estatal y autonómico) y su naturaleza sectorial y $\sin$ un enfoque integrado, es una realidad incuestionable a la que se enfrenta todo estudioso de la materia. Si a ello añadimos que nos hallamos ante un Derecho en evolución constante, donde la legislación motorizada de que habló Carl Schmitt es prácticamente supersónica y que se resiste a dejarse conocer al día, todo ello explicaría las dificultades a las que se enfrentan nuestros Tribunales penales a la hora de resolver los problemas jurídicos que plantea su aplicación efectiva.

Sería necesario, así pues, un enfoque integrador de la materia y un encauzamiento global, que regule de manera singular las diferentes actividades y su incidencia en el medio ambiente, y si bien es verdad, que se observa una tendencia en este sentido, siendo ejemplo de ello la Directiva 96/61 C.E. de prevención y control integrados de la contaminación, la realidad es bien distinta, siendo imprescindible por el momento, para saber qué normas rigen y qué Administración es competente en un determinado sector, hacer una labor integradora de todo el ordenamiento jurídico ambiental ${ }^{35}$.

\footnotetext{
${ }^{34}$ Véase, SILVA SÁNCHEZ, J. M., Delitos contra el medio ambiente, o. c. p. 60

${ }^{35}$ En este sentido, RUIZ DE APODACA ESPINOSA, A. M., Derecho ambiental integrado: la regulación de los lodos de depuradora y de sus destinos, o. c. pp. 29 y ss
} 